Lower oxalate concentrations and higher $\mathrm{pH}$ in the wood cell wall compared to the cell lumen, drives CMF chemistry.

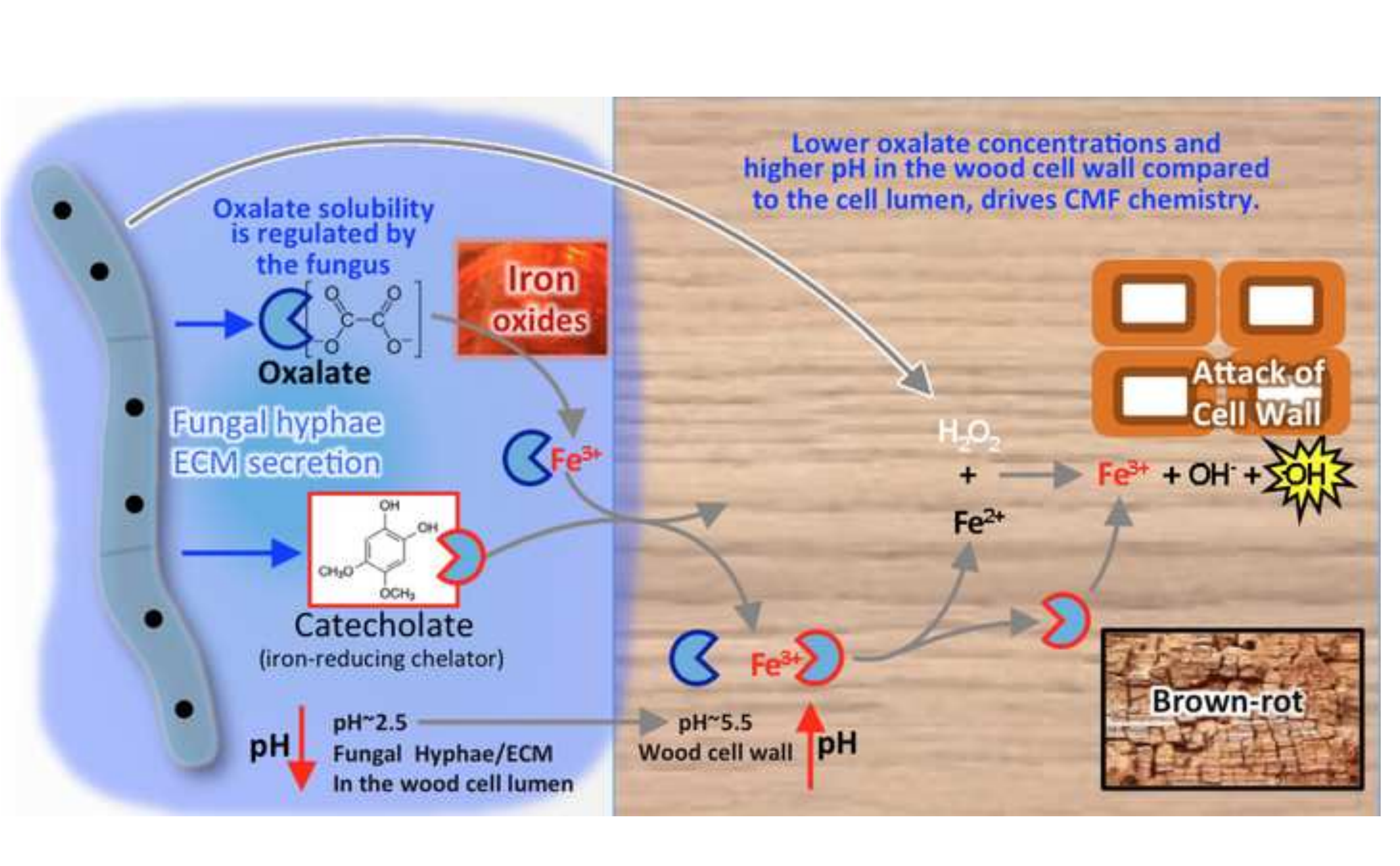

.

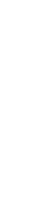

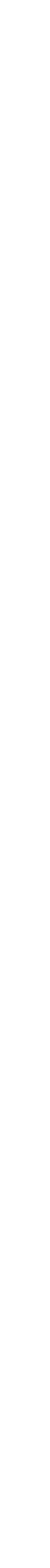

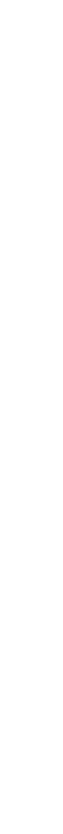

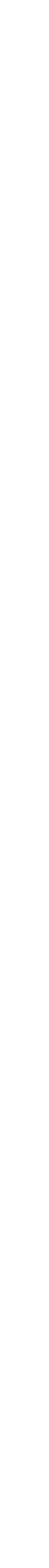

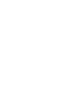




\title{
Iron sequestration in brown-rot fungi by oxalate and the production of reactive oxygen
} species (ROS)

\author{
Yuan Zhu ${ }^{1,2}$, Liangpeng Zhuang ${ }^{2}$, Barry Goodell ${ }^{2, *}$, Jinzhen Cao ${ }^{1, *}$, James Mahaney ${ }^{3}$ \\ ${ }^{1}$ MOE Key Laboratory of Wooden Material Science and Application, Beijing Forestry \\ University, Qinghua East Road 35, Haidian 100083, Beijing, China \\ ${ }^{2}$ Dept. Sustainable Biomaterials, Virginia Tech, Blacksburg, VA. USA \\ ${ }^{3}$ Edward Via Virginia College of Osteopathic Medicine, Blacksburg, VA. USA \\ * Corresponding Author
}

\begin{abstract}
:
The biochemical role of oxalate in the fungal solubilization of iron is well known, but additional information is needed on the role that oxalate plays in the brown-rot decay of lignocellulose. In this study iron sequestration from iron and iron oxide-hydroxides was assessed with regard to the function of a chelator-mediated Fenton (CMF) reaction and the generation of reactive oxygen species (ROS). The reactions conducted at the lowest $\mathrm{pH}$ condition $(\mathrm{pH} 2.0)$ and oxalate concentration $(15 \mu \mathrm{M})$ generated the greatest amount of FeII, suggesting that $\mathrm{pH}$, rather than oxalate concentration may have a greater impact on Fenton reactions, and specifically the CMF reaction. Moreover, iron oxide-hydroxides that were pre-incubated with oxalate prior to the CMF reaction, generated more ROS than the iron oxide-hydroxides without oxalate incubation. This indicates that an enhanced CMF reaction was promoted by iron sequestration due to oxalate incubation, and also supports previous research showing a $\mathrm{pH}$-dependent iron transfer from oxalate to chelators produced by fungi. Although Fenton reactions were enhanced at low $\mathrm{pH}$, the iron transfer reaction was enhanced at higher $\mathrm{pH}$. In a decay environment, this would limit damaging Fenton reactions from occurring in the low $\mathrm{pH}$ environment directly surrounding the fungal hyphae.
\end{abstract}

\section{Key words:}

Oxalate; Iron oxide-hydroxides; Iron sequestration; Brown-rot fungi; Reactive oxygen species

\section{Introduction}

The mechanism of lignocellulose biodegradation is of great interest because of the need to find new environmentally sound methods for the protection of wood and other lignocellulose materials (Goodell et al., 1997; Schultz et al., 2007), and because of interest in bioconversion of lignocellulose in biorefinery applications (Goodell et al., 1997; Ray et al., 2010; Sánchez, 2009). One of the most destructive types of decay, brown-rot decay is characterized by a rapid decrease in strength in early stages because of the extensive holocellulose depolymerization produced within the wood cell wall (Arantes et al., 2012; Cowling, 1961; Zhou et al., 2011). However, all degrading enzymes, including those of brown-rot and white-rot fungi, are too large to penetrate the unaltered microstructure of the cellulosic cell wall, preventing enzymatic attack in early stages of wood degradation (Blanchette, 1995; Highley and Dashek, 1998). Non-specific oxidizing chemistries are known to depolymerize cell wall components; however these chemistries would also be destructive to the fungal hyphae. Research has indicated however 
that brown-rot fungi typically generate their oxidizing chemistries at a distance from the fungal mycelia (Hammel et al., 2002; Hyde and Wood, 1997; Kim et al., 1991). (Arantes et al., 2009)

Several studies have demonstrated that Fenton-like reactions involving $\mathrm{H}_{2} \mathrm{O}_{2}$ and FeII produces reactive oxygen species (ROS), which are the primary oxidizing agents involved in cell wall attack (Hammel et al., 2002; Irbe et al., 2011; Jensen et al., 2001; Koenigs, 1974). Further, research shows that low molecular weight degrading agents produced by brown-rot fungi are capable of diffusing into the wood cell wall to participate in fungal degradation (Goodell et al., 1997; Goodell et al., 2003; Ritschkoff, 1996). This evidence has led to the development of research on a non-enzymatic extracellular mechanism for initial brown-rot decay, known as the chelator-mediated Fenton (CMF) reaction (Arantes et al., 2010; Goodell et al., 1997; Jensen et al., 2001; Xu and Goodell, 2001).

For the CMF to be active in generating ROS though, iron must be available to the organism to be reduced by reductants. Although iron oxide-hydroxides are abundant in most soils and wood, these types of iron are unavailable to most microorganisms until solubilized. In response to iron deficiency, many microorganisms have developed specific iron acquisition systems to sequester iron from its oxide-hydroxide forms by secreting iron high-affinity chelators. Some organisms produce compounds known as siderophores for this purpose (Boukhalfa and Crumbliss, 2002; Crowley et al., 1991; Guerinot and Yi, 1994; Hider, 1984), but other non-siderophore chelators can be generated by fungi as well. Sequestration of iron is important for metabolic processes, and in the brown rot fungi, it is also essential for the CMF reaction to be effective (Arantes et al., 2010; Goodell et al., 1997; Goodell et al., 2003).

Shimazono et al. (1952) first observed the accumulation of oxalate secreted by wood-destroying fungi, which later was identified in the cultures of many different brown-rot and white-rot fungi (Connolly and Jellison, 1995; Espejo and Agosin, 1991; Takao, 1965). Oxalate is not produced by all fungi but has been shown to be involved with fungal decay systems linking degradation mechanisms with multiple ecological functions (Dutton and Evans, 1996; Shimada et al., 1994). Although other roles for oxalate undoubtedly exist, the CMF system supports a role for oxalate in sequestering iron from insoluble oxidized forms to form Fe-Oxalate complexes (Goodell, 2014; Goodell et al., 1997; Hyde and Wood, 1997). Under appropriate conditions, mediated by a $\mathrm{pH}$ shift which occurs between the fungal extracellular matrix (ECM) region and the wood cell wall, iron will be transferred to catecholate/hydroxyquinone chelators to be reduced and initiate the Fenton reaction (Goodell et al., 1997; Hyde and Wood, 1997). The CMF system in the brown rot fungi therefore requires activity from two different types of chelators (Goodell, 2014). Additional information is needed, however, on the role that oxalate plays in the iron transfer reactions, and how this is affected by both oxalate concentration and $\mathrm{pH}$.

Limited research on the iron sequestration by oxalate produced by brown-rot fungi has been conducted. Besides promoting the iron sequestration from its oxide-hydroxides, simultaneously, oxalate can also suppresses the reduction of sequestered iron by chelators dependent upon concentration and $\mathrm{pH}$ (Arantes et al., 2009; Varela and Tien, 2003). It is therefore important to better understand iron sequestration by oxalate and the subsequent reduction of iron by catecholate/hydroxyquinone chelators in the presence of oxalate.

The primary objective of this research was to better understand how iron is sequestered from iron oxide-hydroxides by oxalate over time, and how catecholate chelators may then 
access this iron.

\section{Material and methods}

All reactions in section 2.2-2.4 were conducted in the dark as oxalate would photo-reduce iron in bright light. 2,3 dihydroxybenzoic acid (2,3-DHBA) was used as previously described to mimic the catecholate chelators produced by brown rot fungi.

\subsection{Chemical reagents}

2,3-DHBA, and ferrozine were purchased from Acros Organics (NJ, USA). 5,5-dimethyl-1-pyrroline N-oxide (DMPO) was purchased from Sigma Aldrich. Acetic acid and hydrochloric acid $(\mathrm{HCl})$ were purchased from Spectrum Chemical Manufacturing Corp. For other chemical reagents, including oxalate, potassium chloride $(\mathrm{KCl})$, sodium acetate trihydrate, ferric chloride hexahydrate $\left(\mathrm{FeCl}_{3} \cdot 6 \mathrm{H}_{2} \mathrm{O}\right)$, hydrogen peroxide $\left(\mathrm{H}_{2} \mathrm{O}_{2}\right)$, were all purchased from Fisher Scientific, Fair Lawn, NJ. To obtain naturally occurring iron oxide-hydroxides, freshly prepared $\mathrm{FeCl}_{3}$ [designated as $\mathrm{Fe}(\mathrm{Fre})$ ] was exposed to oxygen for at least one month to produce oxygenated iron compounds, [designated as $\mathrm{Fe}(\mathrm{Oxy})]$.

\subsection{Iron transfer from oxalate to 2,3-DHBA}

$\mathrm{Fe}$ (Fre)-oxalate was produced by incubating $\mathrm{Fe}(\mathrm{Fre})$ with oxalate at a molar ratio of 1:1.5 for $24 \mathrm{~h}$. This ratio was selected to insure chelation of the iron by oxalate. A kinetic study of iron transfer and reduction was then conducted by mixing the iron oxalate with 2,3-DHBA in buffer solution. Two buffers were used: pH 2.2 - Clark and Lubs buffer (100mM); and pH 4.4 - acetate buffer $(100 \mathrm{mM})$. Ferrozine was used as a specific detection agent for FeII. Buffered ferrozine was added last to the mixture, and FeII generation over a $24 \mathrm{~h}$ period was determined against standards at $562 \mathrm{~nm}$ (NanoDrop 2000c). The final reaction mixture contained $30 \mu \mathrm{M} \mathrm{FeCl}_{3}$, $45 \mu \mathrm{M}$ oxalate (except for the control), $2 \mu \mathrm{M} 2,3-\mathrm{DHBA}$ and $250 \mu \mathrm{M}$ ferrozine reagent.

\subsection{ROS production with 2,3-DHBA and oxalate-sequestered iron and detection by spin-trap EPR spectroscopy}

The ROS spin-trap, DMPO (100 mM final concentration) was mixed with $\mathrm{Fe}(\mathrm{Oxy})$-oxalate and 2,3-DHBA $(30 \mu \mathrm{M})$. The two buffers and iron solution were made as overviewed in section 2, with $\mathrm{Fe}(\mathrm{Oxy})$-oxalate produced using $30 \mu \mathrm{M} \mathrm{FeCl}_{3}$ and $45 \mu \mathrm{M}$ oxalate. $\mathrm{H}_{2} \mathrm{O}_{2}(1.5 \mathrm{mM})$ was then added to the reaction mixtures to initiate ROS generation. ROS generation was determined using the spin-trap DMPO and the characteristic 2-line signal for the DMPO spin adduct was detected using electron paramagnetic resonance (EPR) spectroscopy. EPR spectra of the trapped radicals were recorded at room temperature after 5 min of reaction time using a Bruker Biospin E-scan X-band EPR spectrometer. The following settings were used, center field 3468; sweep width, 100G; microwave attenuation, $10 \mathrm{~dB}$; modulation frequency, $86 \mathrm{kHz}$ with $1 \mathrm{G}$ modulation amplitude; time constant $5.12 \mathrm{msec}$ and a receiver gain of 4480 . All spectra were averaged over 16 scans for each sample. Spectra were digitized and recorded to PC using the E-scan software WinEPR, and were analyzed using the same program.

\subsection{Iron sequestration by oxalate}


$\mathrm{Fe}(\mathrm{Oxy})$ was mixed with oxalate in an expanded buffer range of 2.0, 3.5, 4.8, and added to appropriately buffered 2,3-DHBA (as listed in Table 1), with ferrozine added last to monitor FeII generation over a 24 hour span as described in section 2.2. Because ferrozine permanently binds FeII, but not FeIII, as iron is reduced it shifts the reaction conditions by removing FeII from the reaction. For these experiments, this shift was desirable as a means of mimicking the reaction of FeII with oxidants like $\mathrm{H}_{2} \mathrm{O}_{2}$, which would be present in actual brown-rot decay environments, and also would repeatedly react with any FeII generated, oxidizing it to FeIII.

Table 1. Samples for iron sequestration by a kinetic Ferrozine assay. Three $100 \mathrm{mM}$ buffer solutions were used: pH 2.0 (Clark and Lubs buffer) and 3.5 and 4.8 (both acetate buffers) and all samples were made up to $3 \mathrm{ml}$.

\section{Results and discussion}

\subsection{Transfer of iron from oxalate to 2,3-DHBA}

Freshly prepared $\mathrm{FeCl}_{3}$ was mixed with 2,3 DHBA either with or without oxalate. $\mathrm{FeCl}_{3}$ (without oxalate) in the presence of 2,3-DHBA at $\mathrm{pH} 2.2$ was reduced more rapidly than the same mixture at $\mathrm{pH} 4.4$ (Fig. 1.). It is well known that in lower $\mathrm{pH}$ reducing environments, iron is reduced more rapidly and this has been attributed to greater solubility of iron at a low $\mathrm{pH}$ (Goodell et al., 1997). In the presence of 2,3 DHBA, the same interpretation can be made for the accelerated iron reduction at a lower $\mathrm{pH}$.

Fig. 1. Comparison of FeII generation in the presence of 2,3 DHBA and with, or without oxalate at $\mathrm{pH}$ conditions of 2.2 (a) or 4.4 (b). Final reaction mixtures contained $30 \mu \mathrm{M}$ FeIII, $2 \mu \mathrm{M}$ 2,3-DHBA and $250 \mu \mathrm{M}$ Ferrozine reagent. $45 \mu \mathrm{M}$ oxalate was added for the oxalate-containing samples.

$\mathrm{FeCl}_{3}$ that was pre-incubated with oxalate was reduced less rapidly in the presence of 2,3-DHBA than the samples without oxalate. This was observed at both $\mathrm{pHs}$, and has been previously attributed to the formation of stable Fe-Oxalate complexes that impede iron reduction (Arantes et al., 2009). However, in the oxalate-containing samples, iron reduction occurred more slowly, and less iron overall was reduced at $\mathrm{pH} 2.2$ compared to $\mathrm{pH} 4.4$ (Fig. 1), indicating that the $\mathrm{pH} 4.4$ environment was more favorable for iron transfer from oxalate to 2,3-DHBA. Similar findings when oxidized iron was incubated with oxalate were previously observed (Goodell et al. 1997). This data suggests why the $\mathrm{pH}$ differential between the fungal extracellular matrix (ECM) and the wood cell wall, would help to promote iron reduction within the wood cell wall where redox reactions generated by the CMF will promote cell wall deconstruction.

\subsection{ROS production with 2,3-DHBA oxalate-sequestered iron and detection by EPR spin-trap spectroscopy}

EPR spin trapping studies showed that ROS were generated when all species of iron tested were mixed with 2,3 DHBA and $\mathrm{H}_{2} \mathrm{O}_{2}$ (Fig. 2). DMPO will trap both hydroxyl radicals (the four dominant peaks) as well as superoxide radicals (the smaller peaks between the four dominant 
peaks). However at both $\mathrm{pH} 2.2$ and 4.4, samples containing $\mathrm{Fe}(\mathrm{Oxy})$-only displayed a reduced ROS signal as compared to samples with Fe(Fre). This indicates that the oxygenated iron was less able to participate in CMF reactions. In this regard, the lack of available iron is well known in most microbial systems, and for this reason many organisms produce chelators to sequester insoluble iron from the environment (Kraemer, 2004; Neilands, 1995; Schwyn and Neilands, 1987). Prior research has demonstrated that brown rot fungi preferentially produce more catecholate chelators which are capable of sequestering and reducing iron, whereas white rot and other fungi produce other types of chelators such as hydroxamic acids which do not readily reduce iron (Goodell et al., 2006; Goodell et al., 2002; Qi, 2001). However, it must be recognized that free ferrous iron would not typically be available in fungal or soil environments. In the fungal decay environment therefore, the low $\mathrm{pH}$ reduction - which requires soluble iron, would therefore not occur.

Fig. 2. EPR spin-trap spectra when different iron $(30 \mu \mathrm{M})$ species including $\mathrm{Fe}(\mathrm{Fre})$, $\mathrm{Fe}(\mathrm{Oxy})-\mathrm{Oxalate}, \mathrm{Fe}(\mathrm{Oxy})$ were mixed in the presence of 2,3-DHBA $(30 \mu \mathrm{M})$ and $\mathrm{H}_{2} \mathrm{O}_{2}$ (1.5mM) at $\mathrm{pH} 2.2$ (a) and 4.4 (b).

An increased ROS signal was observed by pre-incubating $\mathrm{Fe}(\mathrm{Oxy})$ with oxalate and then mixing with 2,3-DHBA and $\mathrm{H}_{2} \mathrm{O}_{2}$ (Fig. 2). As oxalate is typically produced in early stages of wood decay by the fungi, the sequestration of iron by oxalate from the environment would be expected to occur. This study confirmed that oxalate was able to promote enhanced CMF reactions when iron was sequestered prior to CMF redox reactions. When using oxalate-sequestered oxide-hydroxide iron [ $\mathrm{Fe}(\mathrm{Oxy})-\mathrm{Oxalate}]$, reactions at a higher $\mathrm{pH}$ yielded greater activity in the $\mathrm{CMF}$ reaction. This is because the higher $\mathrm{pH}$ (4.4) was more favorable for the iron transfer from oxalate to 2,3-DHBA as discussed above. In the fungal/wood environment, reactions favoring ROS generation would therefore be favored in the higher $\mathrm{pH}$ environment of the wood cell wall as opposed to the environment directly surrounding the fungal hyphae and within the ECM.

\subsection{Iron sequestration by oxalate}

FeII production was monitored in the presence of oxalate and 2,3-DHBA under conditions dependent on both $\mathrm{pH}$ and the concentration of oxalate.

pH 2.0: At $\mathrm{pH} 2.0$, iron reduction by 2,3-DHBA in $\mathrm{Fe}(\mathrm{Oxy})$ samples was initially greater in the absence of oxalate (Fig. 3a). Only over time (during the 24 hour analysis) was it apparent that oxalate solubilized the iron and made more of it available for reduction by 2,3-DHBA. This was most apparent at the lowest concentration of oxalate tested $(15 \mu \mathrm{M})$. Intuitively, a higher concentration of oxalate will sequester more iron (Ambikadevi and Lalithambika, 2000). However, with increasing concentration of oxalate, even though more iron would have been solubilized, transfer of iron to 2,3-DHBA was reduced, and thus less reduction of iron occurred over time. Therefore oxalate regulation by the fungus, and reduced concentrations which would occur with diffusion into the wood cell wall, would likely play important roles in maintaining appropriate levels of oxalate to permit the transfer of iron to catecholate chelators in the decay environment.

Siderophores and other chelators produced by microorganisms have a high affinity and 
specificity for iron binding and have been reported to assist in iron acquisition from iron oxides (Boukhalfa and Crumbliss, 2002; Kraemer, 2004). However, chelators like 2,3-DHBA require additional chelators like oxalate to sequester iron more efficiently in $\mathrm{pH} 2.0$ conditions. In this regard, we suggest that $\mathrm{pH}$ reduction is less important for iron sequestration by brown rot fungi, and secretion of oxalate or other compounds by brown-rot fungi is necessary for the solubilization of $\mathrm{Fe}(\mathrm{Oxy})$ forms in the environment. Ligand adsorption, metal detachment and proton adsorption (Stumm and Furrer, 1987) all play a role in these reactions. However, it is apparent, as demonstrated in section 3.1 and 3.2 that control of $\mathrm{pH}$ and the generation of a $\mathrm{pH}$ differential can aid in the generation of ROS in appropriate locations so that less damage may occur to the fungal hyphae and ROS can be generated within the wood cell wall.

Fig. 3. Kinetic iron sequestration by oxalate over a range of concentrations, including $15 \mu \mathrm{M}$

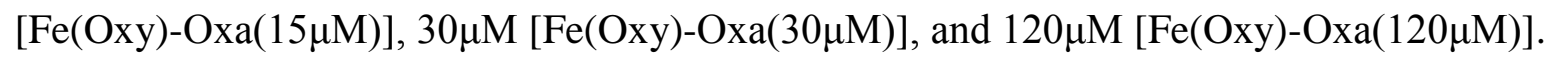
Reactions were run at pH 2.0 (a), pH 3.5 (b) and pH 4.8 (c).

pH 3.5 and 4.8: Although similar trends relative to the role of oxalate in solubilizing iron at $\mathrm{pH} 2.0$ was observed at the higher $\mathrm{pHs}$ tested, iron reduction was less at $\mathrm{pH} 3.5$ (Fig. 3b.) and lesser still at $\mathrm{pH} 4.8$ (Fig. 3c). It is well known that lower $\mathrm{pH}$ environments function as reducing environments, and this data confirms this. The presence of two different types of chelators, which is required in CMF reactions, complicates the findings and so it is useful to separate out the roles of the two types of chelators. Even though lesser amounts of iron are reduced overall at a higher $\mathrm{pH}$, and this would also be expected to occur in the wood cell wall, it is important to recognize the reduction of large amounts of iron may not be necessary to initiate CMF deconstruction of the wood cell wall. The more critical issue is a mechanism to allow the abundant, but unavailable, $\mathrm{Fe}(\mathrm{Oxy})$ forms of iron in the environment to be accessed by the CMF fungal mechanism. The production of oxalate permits this to occur, but it does not generate the reduced iron necessary for Fenton reactions. Only catecholate chelators permit this reduction to initiate ROS generation. As demonstrated in Fig. 1 and 2, these reactions proceed in the presence of oxalate. Therefore, as long as limited amounts of iron can be sequestered by oxalate at the lower $\mathrm{pHs}$ around the fungal hyphae and in the aqueous environment of the ECM, when the oxalate-sequestered iron diffuses into a higher $\mathrm{pH}$ environment, and in the presence of a catecholate chelator like 2,3-DHBA, iron reduction will occur. Redox cycling of the iron will then permit multiple moles of ROS species to be generated for each mole of cateholate chelator produced (Pracht et al., 2001; Qian et al., 2002).

These data confirm the necessity of oxalate control by the fungus (Connolly and Jellison, 1995; Espejo and Agosin, 1991; Schilling and Jellison, 2005) and suggest that further research is needed in this area, but also on earlier reports indicating that control of oxalate concentration may be controlled not only by oxalate secretion, but also by the solubilization and recrystallization of oxalate on the fungal hyphae surface and within the ECM (Connolly and Jellison, 1995; Zhuang et al., 2015).

\section{Conclusion}

Oxalate-sequestered iron was reduced by the chelator (2,3-DHBA) permitting the generation of ${ }^{\circ} \mathrm{OH}$ in the presence of $\mathrm{H}_{2} \mathrm{O}_{2}$. The presence of oxalate suppressed, but did not stop 
iron reduction, although the amount of iron reduction by 2,3-DHBA was dependent upon the oxalate concentration. Both $\mathrm{pH}$ and oxalate concentration played an important role in sequestering iron from oxidized iron for subsequent Fenton reactions. Our data suggest that the secretion of oxalate by brown-rot fungi is essential to making insoluble and unavailable forms of iron in the environment available for the non-enzymatic degradation via the CMF reaction. Iron sequestration by oxalate was enhanced at lower $\mathrm{pH}$ environments, but oxalate concentration appeared to play a greater role in overall iron reduction, and may also do so in brown-rot decay mechanisms. These results suggest that the secretion of oxalate by brown-rot fungi enhances the CMF reaction in early stages of brown-rot decay. These findings provide evidence for the previous theory of oxalate regulation by decay fungi, including oxalate biosynthesis and its metabolism (Evans, 1994; Schilling, 2006; Schilling and Jellison, 2005).

\section{Acknowledgement}

Mr. Zhu was financially supported in part by the Forestry Industry Research Special Funds for Public Welfare Projects (\#201204702-B2), China Scholarship Council (\#201406510014). This work was also supported in part by the USDA-HATCH Project S-1041 VA-136288, and by The Research Council of Norway (243663/E50 BioMim). The authors also thank Dr. Xueyang Feng for providing Nanodrop 2000c spectrophotometer.

\section{References}

Ambikadevi, V. R. and Lalithambika, M. (2000). "Effect of organic acids on ferric iron removal from iron-stained kaolinite." Applied Clay Science 16(3): 133-145.

Arantes, V., Jellison, J. and Goodell, B. (2012). "Peculiarities of brown-rot fungi and biochemical Fenton reaction with regard to their potential as a model for bioprocessing biomass." Applied Microbiology and Biotechnology 94(2): 323-338.

Arantes, V., Milagres, A. M. F., Filley, T. R. and Goodell, B. (2010). "Lignocellulosic polysaccharides and lignin degradation by wood decay fungi: the relevance of nonenzymatic Fenton-based reactions." Journal of Industrial Microbiology \& Biotechnology 38(4): 541-555.

Arantes, V., Qian, Y., Milagres, A. M. F., Jellison, J. and Goodell, B. (2009). "Effect of pH and oxalic acid on the reduction of $\mathrm{Fe}^{3+}$ by a biomimetic chelator and on $\mathrm{Fe}^{3+}$ desorption/adsorption onto wood: Implications for brown-rot decay." International Biodeterioration \& Biodegradation 63(4): 478-483.

Blanchette, R. A. (1995). "Degradation of the lignocellulose complex in wood." Canadian Journal of Botany 73(S1): 999-1010.

Boukhalfa, H. and Crumbliss, A. L. (2002). "Chemical aspects of siderophore mediated iron transport." BioMetals 15(4): 325-339.

Connolly, J. H. and Jellison, J. (1995). "Calcium translocation, calcium oxalate accumulation, and hyphal sheath morphology in the white-rot fungus Resinicium bicolor." Canadian Journal of Botany 73(6): 927-936.

Cowling, E. B. 1961. Comparative biochemistry of the decay of sweetgum sapwood by white-rot and brown-rot fungi: US Dept. of Agriculture.

Crowley, D., Wang, Y., Reid, C. and Szaniszlo, P. (1991). "Mechanisms of iron acquisition from siderophores by microorganisms and plants." Plant and Soil 130(1-2): 179-198.

Dutton, M. V. and Evans, C. S. (1996). "Oxalate production by fungi: its role in pathogenicity and ecology in the soil environment." Canadian journal of microbiology 42(9): 881-895.

Espejo, E. and Agosin, E. (1991). "Production and degradation of oxalic acid by brown rot fungi." Applied and 
Environmental Microbiology 57(7): 1980-1986.

Evans, C. (1994). "Enzymes and small molecular mass agents with lignocellulose degradation." FEMS microbiology reviews 13: 235-240.

Goodell, B. 2014. The Chelator Mediated Fenton System in the Brown Rot Fungi: Details of the Mechanism, and Reasons Why it has Been Ineffective as a Biomimetic Treatment in some Biomass Applications- a Review, The 45th IRG Annual Meeting St George, Utah, USA, 11-15 May, 2014.

Goodell, B., Daniel, G., Jellison, J. and Qian, Y. (2006). "Iron-reducing capacity of low-molecular-weight compounds produced in wood by fungi." Holzforschung 60(6): 630-636.

Goodell, B., Jellison, J., Liu, J., Daniel, G., Paszczynski, A., Fekete, F., Krishnamurthy, S., Jun, L. and Xu, G. (1997). " Low molecular weight chelators and phenolic compounds isolated from wood decay fungi and their role in the fungal biodegradation of wood." Journal of Biotechnology 53(2): 133-162.

Goodell, B., Nicholas, D. and Schultz, T. 2003. Brown-rot fungal degradation of wood: our evolving view. In Brown-rot fungal degradation of wood: our evolving view, Current knowledge of wood deterioration mechanisms and its impact on biotechnology and wood preservation. Symposium at the 221st National Meeting of the American Chemical Society, San Diego, California, USA, 1-5 April 2001.

Goodell, B., Qian, Y., Jellison, J., Richard, M. and Qi, W. (2002). "Lignocellulose oxidation by low molecular weight metal-binding compounds isolated from wood degrading fungi: A comparison of brown rot and white rot systems and the potential application of chelator-mediated Fenton reactions." Progress in Biotechnology 21: 37-47.

Guerinot, M. L. and Yi, Y. (1994). "Iron: nutritious, noxious, and not readily available." Plant Physiology 104(3): 815.

Hammel, K. E., Kapich, A. N., Jensen Jr, K. A. and Ryan, Z. C. (2002). "Reactive oxygen species as agents of wood decay by fungi." Enzyme and Microbial Technology 30(4): 445-453.

Hider, R. C. 1984. Siderophore mediated absorption of iron. In Siderophore mediated absorption of iron, Siderophores from Microorganisms and Plants, 25-87: Springer Berlin Heidelberg.

Highley, T. L. and Dashek, W. V. (1998). "Biotechnology in the study of brown-and white-rot decay." Forest products biotechnology: 15-36.

Hyde, S. M. and Wood, P. M. (1997). "A mechanism for production of hydroxyl radicals by the brown-rot fungus Coniophora puteana: Fe (III) reduction by cellobiose dehydrogenase and Fe (II) oxidation at a distance from the hyphae." Microbiology 143(1): 259-266.

Irbe, I., Andersone, I., Andersons, B., Noldt, G., Dizhbite, T., Kurnosova, N., Nuopponen, M. and Stewart, D. (2011). "Characterisation of the initial degradation stage of Scots pine (Pinus sylvestris L.) sapwood after attack by brown-rot fungus Coniophora puteana." Biodegradation 22(4): 719-728.

Jensen, K. A., Houtman, C. J., Ryan, Z. C. and Hammel, K. E. (2001). "Pathways for Extracellular Fenton Chemistry in the Brown Rot Basidiomycete Gloeophyllum trabeum." Applied and Environmental Microbiology 67(6): 2705-2711.

Kim, Y. S., Goodell, B. and Jellison, J. (1991). "Immuno-Electron Microscopic Localization of Extracellular Metabolites in Spruce Wood Decayed by Brown-Rot Fungus." Holzforschung 45(5): 389-393.

Koenigs, J. (1974). "Hydrogen peroxide and iron: a proposed system for decomposition of wood by brown-rot basidiomycetes [Pinus taeda, Liquidambar styraciflua, fungus diseases]." Wood and Fiber.

Kraemer, S. M. (2004). "Iron oxide dissolution and solubility in the presence of siderophores." Aquatic Sciences 66(1): 3-18.

Neilands, J. B. (1995). "Siderophores structure and function of microbial iron transport compounds." journal of Biological Chemistry 270(45): 26723-26726. 
Pracht, J., Boenigk, J., Isenbeck-Schröter, M., Keppler, F. and Schöler, H. (2001). "Abiotic Fe (III) induced mineralization of phenolic substances." Chemosphere 44(4): 613-619.

Qi, W. 2001. Characterization of biochelators, membrane redox systems, and quinone reductases from wood degrading basidiomycetes, The University of Maine.

Qian, Y. H., Goodell, B. and Felix, C. C. (2002). "The effect of low molecular weight chelators on iron chelation and free radical generation as studied by ESR measurement." Chemosphere 48(1): 21-28.

Ray, M. J., Leak, D. J., Spanu, P. D. and Murphy, R. J. (2010). "Brown rot fungal early stage decay mechanism as a biological pretreatment for softwood biomass in biofuel production." Biomass and bioenergy 34(8): 1257-1262. Ritschkoff, A. C. 1996. Decay mechanisms of brown-rot fungi: Technical Research Centre of Finland. Sánchez, C. (2009). "Lignocellulosic residues: Biodegradation and bioconversion by fungi." Biotechnology Advances 27(2): 185-194.

Schilling, J. S. 2006. Oxalate production and cation translocation during wood biodegredation by fungi. Schilling, J. S. and Jellison, J. (2005). "Oxalate regulation by two brown rot fungi decaying oxalate-amended and non-amended wood." Holzforschung 59(6): 681-688.

Schultz, T. P., Nicholas, D. D. and Preston, A. F. (2007). "A brief review of the past, present and future of wood preservation." Pest Management Science 63(8): 784-788.

Schwyn, B. and Neilands, J. B. (1987). "Universal chemical assay for the detection and determination of siderophores." Analytical Biochemistry 160(1): 47-56.

Shimada, M., Ma, D.-B., Akamtsu, Y. and Hattori, T. (1994). "A proposed role of oxalic acid in wood decay systems of wood-rotting basidiomycetes." FEMS microbiology reviews 13(2): 285-296.

Stumm, W. and Furrer, G. 1987. The Dissolution of Oxides and Aluminum Silicates: Examples of Surface-coordination-controlled Kinetics. New York,: Wiley and Sons.

Takao, S. (1965). "Organic acid production by basidiomycetes I. Screening of acid-producing strains." Applied microbiology 13(5): 732-737.

Varela, E. and Tien, M. (2003). "Effect of pH and Oxalate on Hydroquinone-Derived Hydroxyl Radical Formation during Brown Rot Wood Degradation." Applied and Environmental Microbiology 69(10): 6025-6031.

Xu, G. and Goodell, B. (2001). "Mechanisms of wood degradation by brown-rot fungi chelator-mediated cellulose degradation and binding of iron by cellulose." Journal of Biotechnology 87(1): 43-57.

Zhou, T., Winkelmann, G., Dai, Z.-Y. and Hider, R. C. (2011). "Design of clinically useful macromolecular iron chelators." Journal of Pharmacy and Pharmacology 63(7): 893-903.

Zhuang, L., Guo, W., Feng, X. and Goodell, B. (2015). "Investigating Oxalate Biosynthesis in Wood-decaying Fungus Gloeophyllum trabeum using ${ }^{13} \mathrm{C}$ Metabolic Flux Analysis". In review. 
Fig. 1. Comparison of FeII generation in the presence of 2,3 DHBA and with, or without oxalate at $\mathrm{pH}$ conditions of 2.2 (a) or 4.4 (b). Final reaction mixtures contained $30 \mu \mathrm{M}$ FeIII, $2 \mu \mathrm{M} 2,3$-DHBA and $250 \mu \mathrm{M}$ Ferrozine reagent. $45 \mu \mathrm{M}$ oxalate was added for the oxalate-containing samples.

Fig. 2. EPR spin-trap spectra when different iron $(30 \mu \mathrm{M})$ species including Fe(Fre), $\mathrm{Fe}(\mathrm{Oxy})-\mathrm{Oxalate}, \mathrm{Fe}(\mathrm{Oxy})$ were mixed in the presence of 2,3-DHBA $(30 \mu \mathrm{M})$ and $\mathrm{H}_{2} \mathrm{O}_{2}(1.5 \mathrm{mM})$ at $\mathrm{pH} 2.2$ (a) and 4.4 (b).

Fig. 3. Kinetic iron sequestration by oxalate over a range of concentrations, including $15 \mu \mathrm{M}[\mathrm{Fe}(\mathrm{Oxy})-\mathrm{Oxa}(15 \mu \mathrm{M})], 30 \mu \mathrm{M}[\mathrm{Fe}(\mathrm{Oxy})-\mathrm{Oxa}(30 \mu \mathrm{M})]$, and $120 \mu \mathrm{M}$ $[\mathrm{Fe}(\mathrm{Oxy})-\mathrm{Oxa}(120 \mu \mathrm{M})]$. Reactions were run at pH 2.0 (a), pH 3.5 (b) and pH 4.8 (c). 


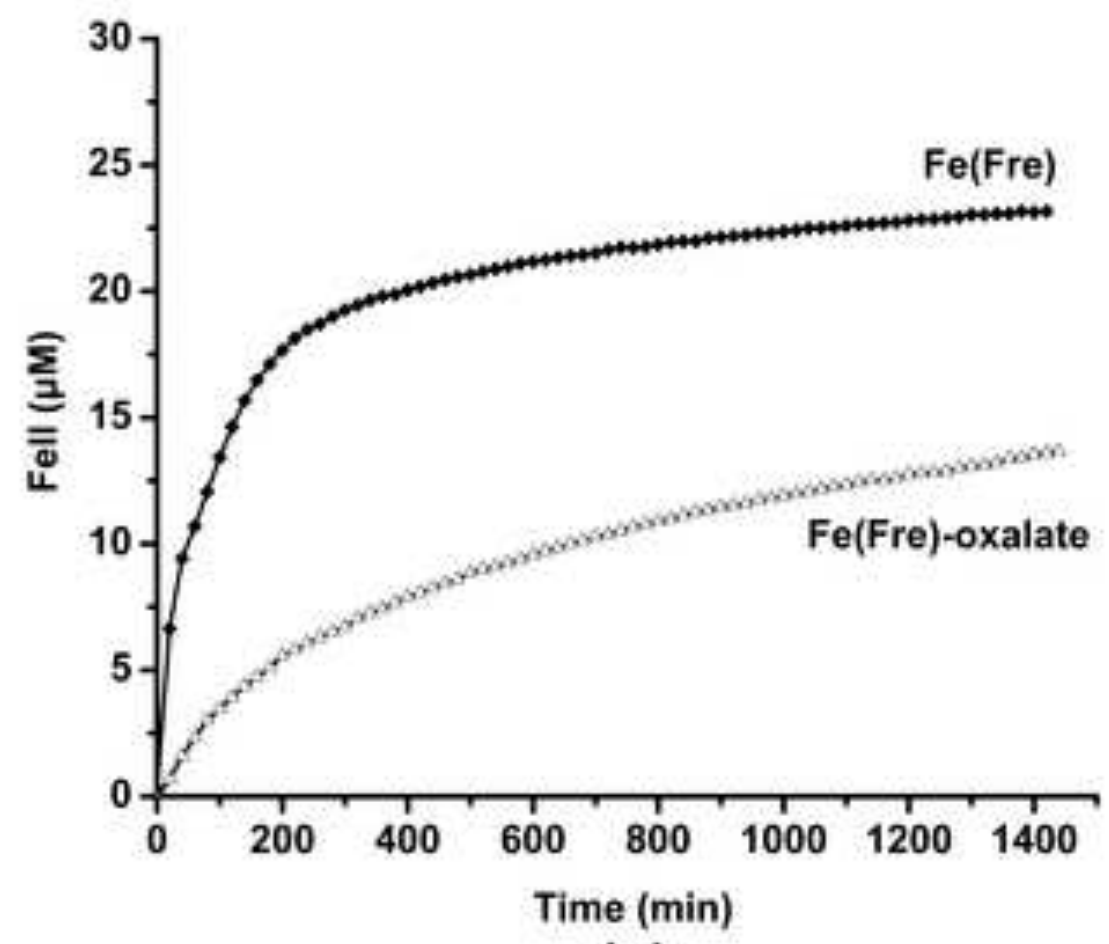

(a)

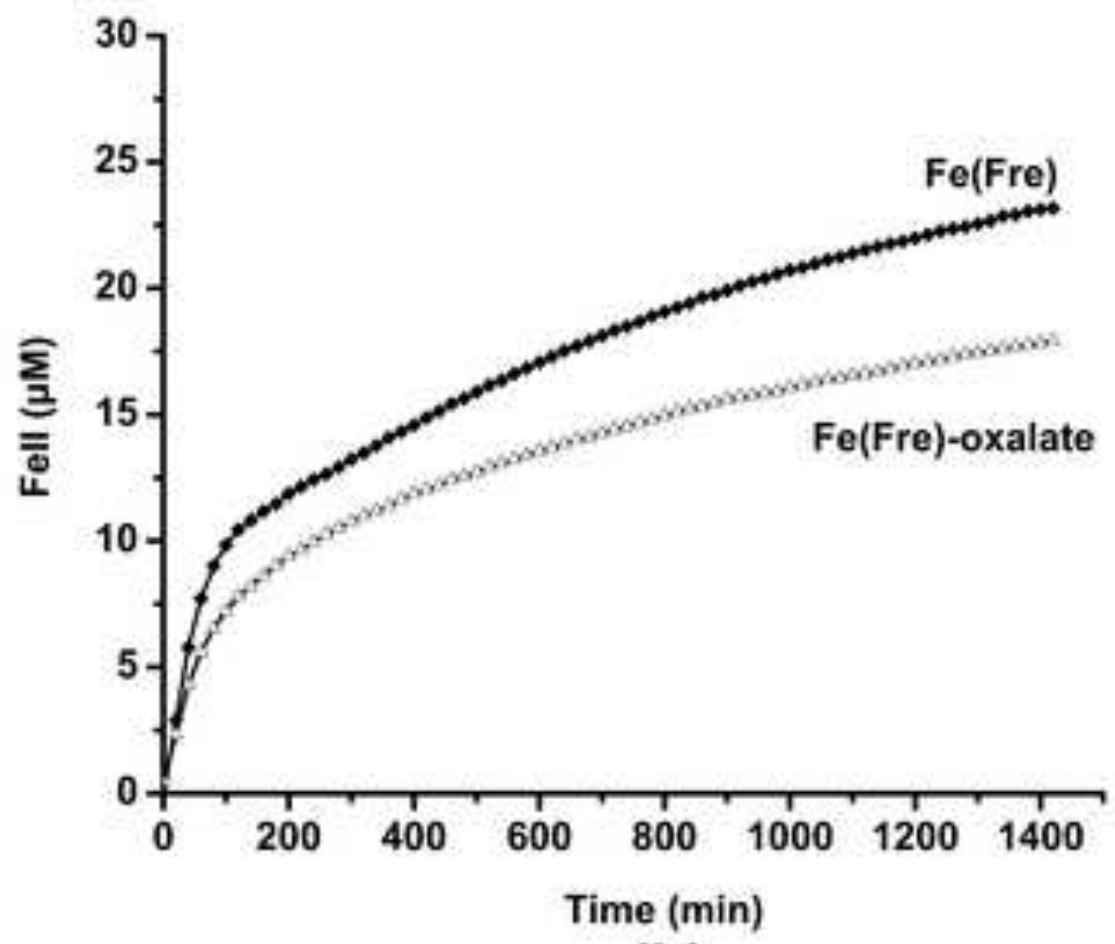

(b) 

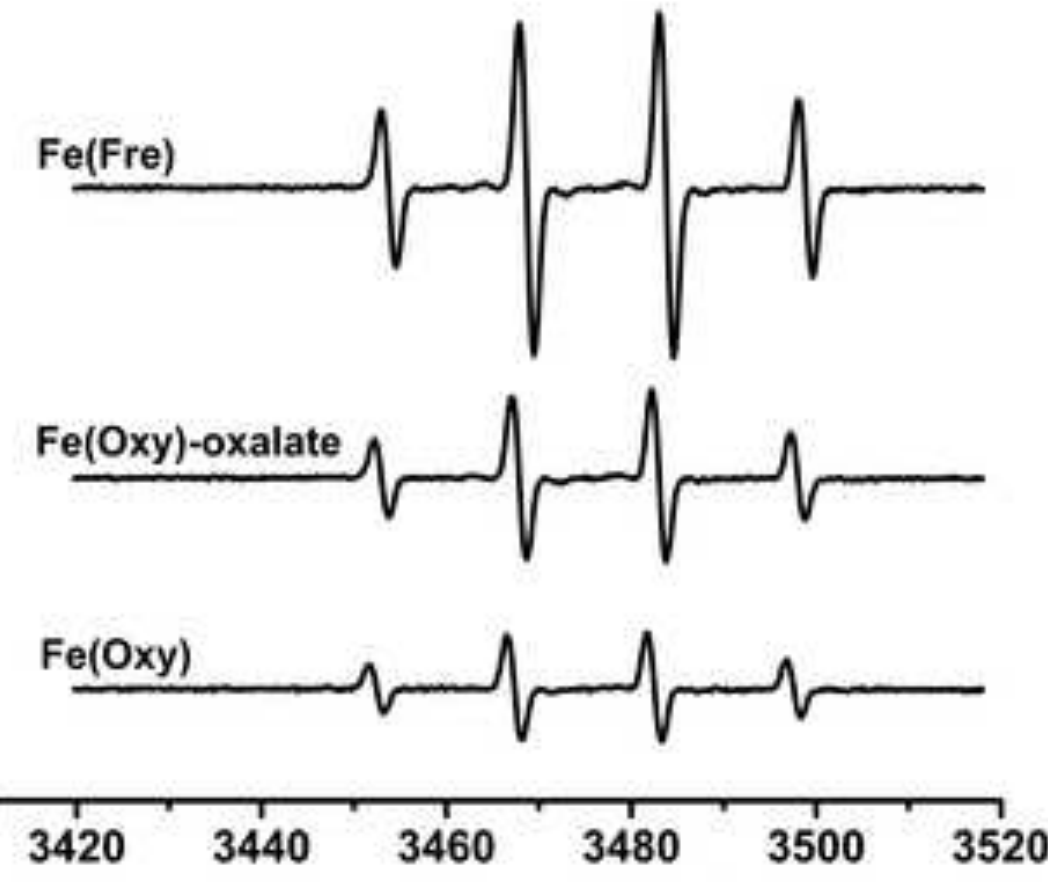

Magnetic field (Gauss)

(a)
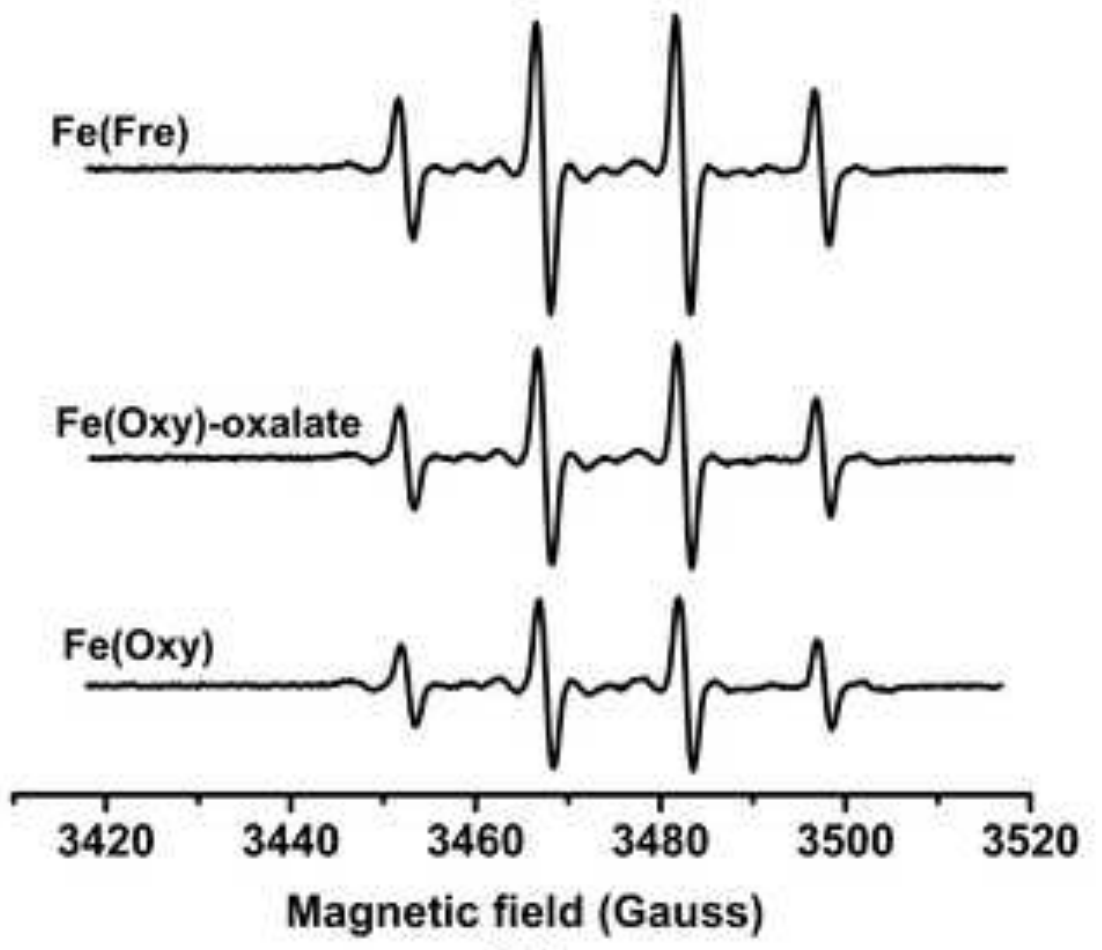

(b) 


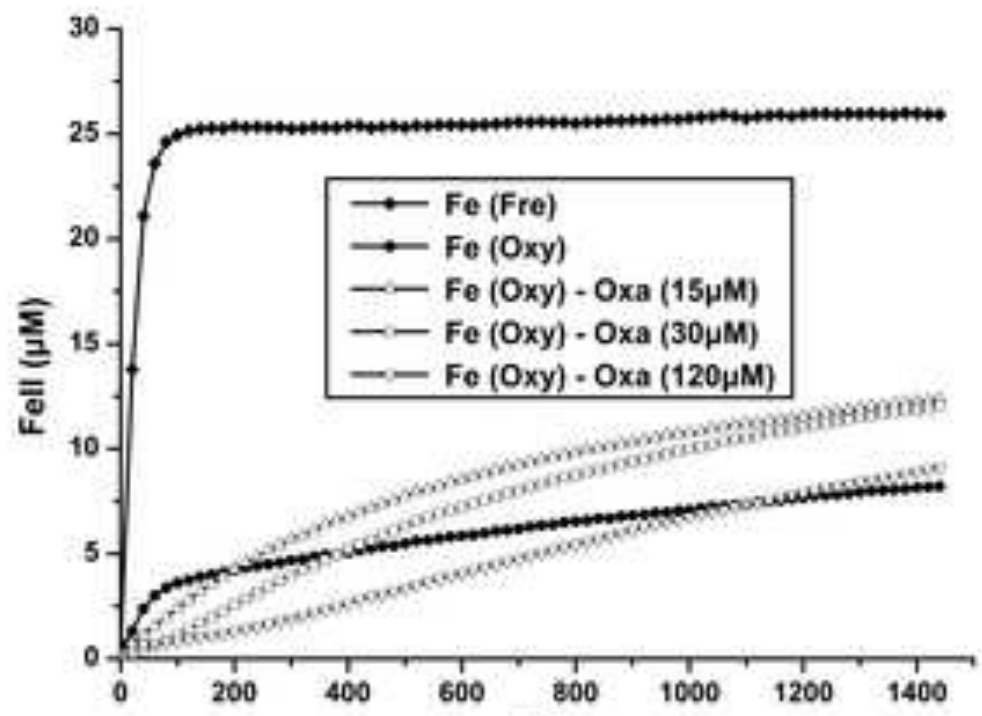

(a)

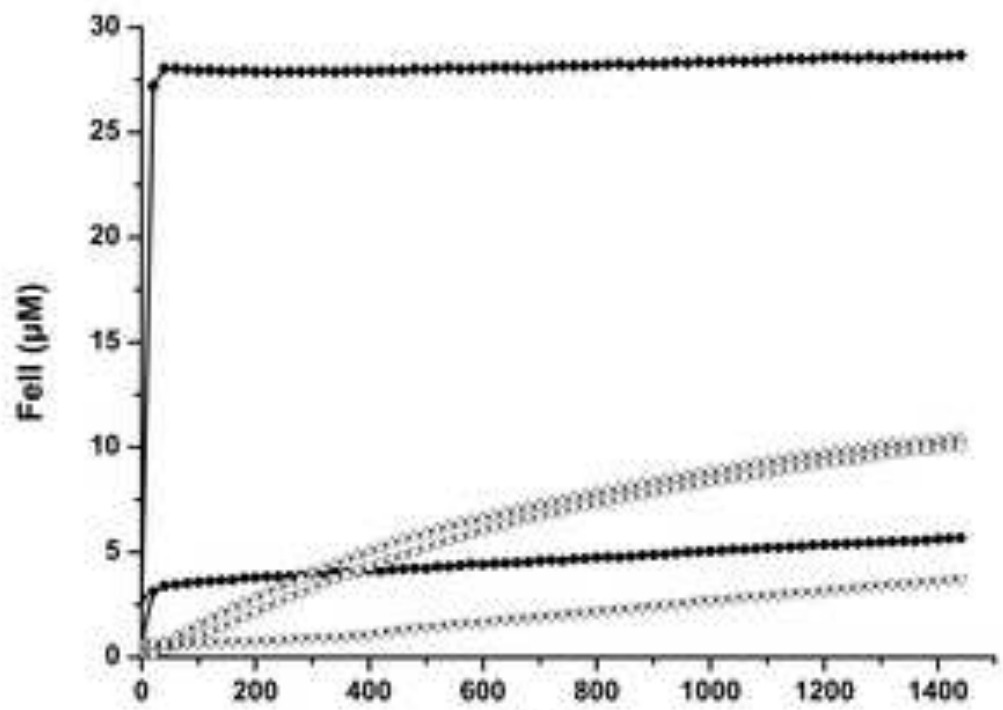

(b)

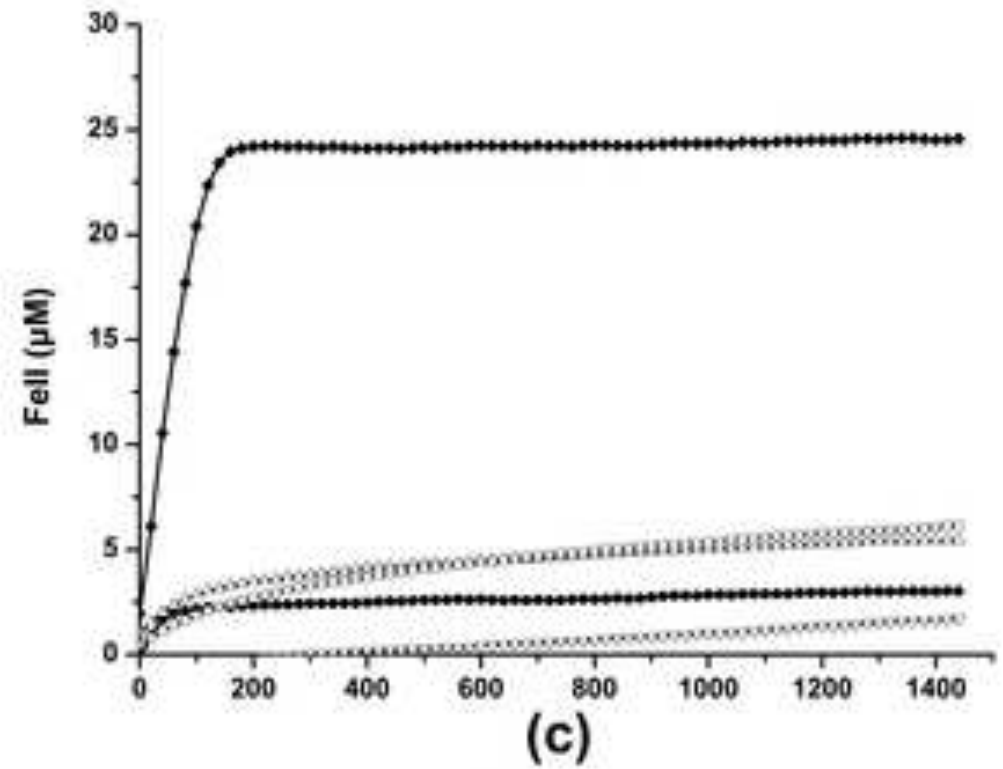

Time (min) 
Table 1. Samples for iron sequestration by a kinetic Ferrozine assay. Three $100 \mathrm{mM}$ buffer solutions were used: $\mathrm{pH} 2.0$ (Clark and Lubs buffer) and 3.5 and 4.8 (both acetate buffers) and all samples were made up to $3 \mathrm{ml}$.

\begin{tabular}{ccccccc}
\hline \multirow{2}{*}{ SAMPLE } & \multicolumn{2}{c}{ Iron $(\mu \mathrm{M})$} & $\begin{array}{c}\text { Oxalate } \\
(\mu \mathrm{M})\end{array}$ & $\begin{array}{c}2,3-\mathrm{DHBA} \\
(\mu \mathrm{M})\end{array}$ & $\begin{array}{c}\text { Ferrozine } \\
(\mu \mathrm{M})\end{array}$ \\
\cline { 2 - 6 } & $\mathrm{Fe}(\mathrm{Fre})$ & $\mathrm{Fe}(\mathrm{Oxy})$ & 30 & 0 & 30 & 250 \\
$\mathrm{Fe}(\mathrm{Oxy})$ & - & 30 & 15 & 30 & 250 \\
$\mathrm{Fe}($ Oxy)-Oxa $(15 \mu \mathrm{M})$ & - & 30 & 30 & 30 & 250 \\
$\mathrm{Fe}($ Oxy)-Oxa $(30 \mu \mathrm{M})$ & - & 30 & 120 & 30 & 250 \\
$\mathrm{Fe}($ Oxy)-Oxa $(120 \mu \mathrm{M})$ & - & 30 & 0 & 30 & 250 \\
$\mathrm{Fe}(\mathrm{Fre})$ & 30 & - & 0
\end{tabular}

